\title{
Use of prescription stimulant for Attention Deficit Hyperactivity Disorder in Aboriginal children and adolescents: a linked data cohort study
}

\author{
Manonita Ghosh*, C. D’Arcy J. Holman and David B. Preen
}

\begin{abstract}
Background: Increasing recognition of Attention Deficit Hyperactivity Disorder (ADHD) among Aboriginal children, adolescents and young adults is a public health challenge. We investigated the pattern of prescription stimulants for ADHD among Aboriginal individuals in Western Australia (WA).

Methods: Using a whole-population-based linked data we followed a cohort of individuals born in WA from 1980-2005, and their parents were born in Australia, to identify stimulant prescription for ADHD derived from statutory WA stimulant prescription dispensing between 2003 and 2007. Parental link was ascertained through WA Family Connections Genealogical Linkage System. Cox proportional hazards regression (HR) models were performed to determine the association between stimulant use and Aboriginal and non-Aboriginal status.

Results: Of the total cohort of 186,468 , around $2 \%(n=3677)$ had prescription stimulants for ADHD. Individuals with both Aboriginal parents were two-thirds (HR 0.33, $95 \% \mathrm{Cl} 0.26-0.42$ ), and with only Aboriginal mother were one-third (HR 0.69, $95 \%$ Cl 0.53-0.90) less likely to have stimulants, compared to individuals with non-Aboriginal parents. HR in Aboriginals was $62 \%$ lower (HR 0.35, $95 \% \mathrm{Cl} 0.25-0.49$ ) in metropolitan areas, and $72 \%$ lower (HR 0.28, $95 \% \mathrm{Cl} 0.20-0.38)$ in non-metropolitan areas, than non-Aboriginals. The risk for simulant use was four times higher among Aboriginal boys than Aboriginal girls (HR 4.08, 95 \% Cl, 2.92-5.69).

Conclusion: Aboriginal cultural understanding of ADHD and attitude towards stimulant medication serve as a determinant of their access to health services. Any ADHD intervention and policy framework must take into account a holistic approach to Aboriginal culture, beliefs and individual experience to provide optimal care they need.
\end{abstract}

\section{Background}

Attention Deficit Hyperactivity Disorder (ADHD) has been defined as a common childhood-onset neurodevelopmental disorder characterized by severe inattention, impulsivity and hyperactivity which can be associated with significant educational and social impairment [1]. Psychostimulant medications such as methylphenidate and dexamphetamine are often recommended as a firstline modality for treating ADHD [2]. Despite extensive research into factors contributing to $\mathrm{ADHD}$, the

\footnotetext{
* Correspondence: manonita.ghosh@uwa.edu.au

Centre for Health Services Research, School of Population Health, University of Western Australia, 35 Stirling Highway, Crawley, WA 6009, Australia
}

aetiology and pathogenesis of the condition are poorly understood. It may be influenced by a combination of genetic and environmental factors [3-5]. As is true with most mental and developmental disorders, there is not a definitive test for ADHD, because diagnosis and classification primarily rely on observed or self-reported behaviours. Moreover, the interpretations of the severity of those behaviours and whether they should be described as abnormal are subjective [6].

In Australia, there has been an increasing recognition of ADHD symptoms among Aboriginal children and adolescents than those in the non-Aboriginal population. Zubrick et al. [7] identified $15 \%$ Aboriginal children compared to $9.7 \%$ non-Aboriginals at the same age were 
at high risk of clinically significant hyperactivity. Yet, we do not have a clear understanding of the determinants that may account for this disparity. People with ADHD are over-represented in criminal justice system [8], and the rates of incarceration are reported high among Aboriginal young [9]. The prevalence of ADHD is higher among people living in low socioeconomic condition $[10,11]$. It is well established that Aboriginal children are socially and economically disadvantaged with a lower life expectancy and less than equal opportunity. Whether the higher manifestation of ADHD symptoms in Aboriginal children and adolescents is a true prevalence of clinical ADHD, or their unique learning and behavioural patterns [12] that may erroneously lead to ADHD diagnosis pause a question.

There remains a dearth of research examining the degree to which ADHD behaviour is perceived as a problem and stimulant treatment is sought for ADHD in Aboriginal communities. Aboriginals place a holistic concept of mental illness including culture and spirituality, family and community kinships, historical, social and economic factors, fear, education and loss [13] which may construct a different attitude towards Western biomedical diagnostic labels and treatment for ADHD behaviour to that of mainstream Australians. This study reports the first whole-population-based Australian study of prescription stimulant pattern for ADHD among Aboriginals. In this paper the term "Aboriginal" encompasses both Aboriginal and Torres Strait Islanders as was approved as appropriate to use in scientific publications [14].

\section{Methods}

\section{Study population}

The study population comprised a retrospective cohort of all children, adolescents and young adults who were born in WA from 1980-2005, and their parents were born in Australia, and were stratified by their parents' Aboriginal and non-Aboriginal status. The cohort was then followed through to identify their first commencement of prescription stimulant for ADHD between 2003 and 2007. Records for still-births, parents born overseas, unknown/missing Aboriginal identity and death before 2003 were excluded, leaving 186,468 individuals for analysis. The selection criteria and process are shown in Fig. 1.

\section{Data sources}

Data were extracted from the WA Register of Birth, Death Registry, Midwives' Notification System (MNS) and Monitoring of Drugs of Dependence Systems through WA Data Linkage System which links databases using probabilistically matching techniques [15], and is known to achieve high level of linkage sensitivity (95$99 \%$ ) and specificity (98-99 \%) [16]. The WA Family

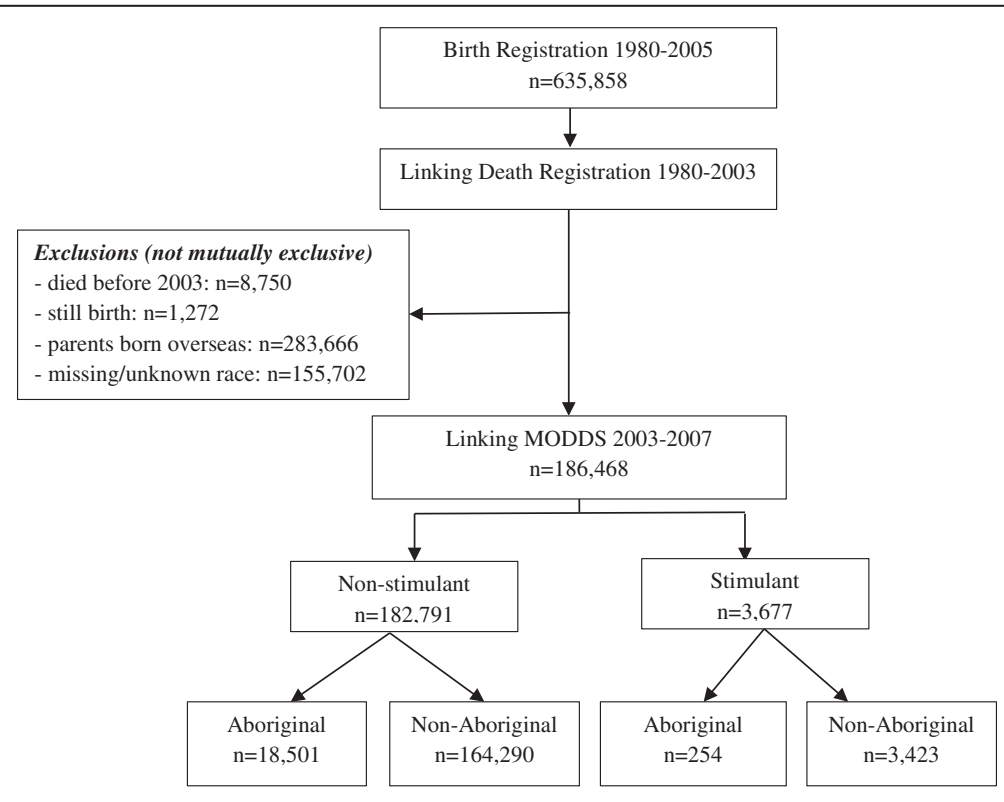

MODDS= Monitoring of Drugs of Dependence System

Fig. 1 Aboriginal and non-Aboriginal cohort identification, group selection and exclusion criteria 
Connections Genealogical Database was linked to ascertain parent-child relationships [17].

\section{Variables and measurements}

The outcome measure was at least one record of prescription stimulant (methylphenidate and/or dexamphetamine) dispensing for ADHD at any time during 2003-2007. Data was collected on a range of demographic factors including sex, Aboriginality, geographical remoteness, socioeconomic disadvantage and mother's age. Parents' Aboriginal status based on self-identification was derived from birth registry and MNS. The birth registry collects Aboriginal status of both parents, while the MNS collects information of the mothers only. Parents were recorded in birth registry as 'Aboriginal' 'Aboriginal/TSI', 'Torres Strait Islander', 'Yes Aboriginal, 'Not Aboriginal, 'unknown', and MNS data was coded as 'Aboriginal/TSI,' 'Caucasian' and 'other'. For this analysis all 'Aboriginal' and 'Torres Strait Islander' records were referred to as Aboriginal; and 'Caucasian,' Not Aboriginal' and 'other' records as non-Aboriginal. Aboriginal people are known to be under-identified or misidentified due to the fact that people may not be prepared to disclose their Aboriginal status depending on the situation [18]. Therefore, parents was considered Aboriginal if they had at least one record showing as an Aboriginal/or Torres Strait Islander in either birth registry or MNS datasets. As such, a parent, identified as Aboriginal in one dataset and nonAboriginal in the other, was considered as Aboriginal to maximise reporting of Aboriginal people in this study [19].

Geographical remoteness was measured using the Accessibility/Remoteness Index of Australia (ARIA) [20] of the Australian Census, using whichever of the 1996, 2001 or 2006 indices were closest to the year of cohort entry. ARIA scores were grouped into three levels: metropolitan, rural and remote, with metropolitan used as the reference category indicating high accessibility according to residential postcode at the time of birth. Socioeconomic disadvantage was ascertained according to the Index of Relative Socio-Economic Disadvantage (IRSD), a summary measure of Socio-Economic Indexes for Areas (SEIFA) that focused on disadvantage in terms of accessibility to education, employment and income [21]. The IRSD scores were then groups into quintiles ranging from most disadvantaged to least disadvantaged. Similar to ARIA, SEIFA score was derived from the national census years 1996, 2001, or 2006, using the index closest to the time of birth.

\section{Statistical analysis}

Descriptive statistics were calculated for all baseline demographic characteristics of the study sample, stratified by stimulant use group. The associations between stimulant use and potential predictors including gender, age, Aboriginality, geographical remoteness and socioeconomic disadvantage were investigated using univariate and multivariate Cox proportional hazards regression (HR) models with a follow-up time 31 of December 2007. Multiple linear regression models were also fitted to compare ages of individuals at initial stimulant use during 2003-2007. A two-sided $p$-value of $<0.05$ was considered statistically significant in all analyses. Missing values for each variable were entered as a separate exposure category in order to include all subjects in the analyses. Statistical analyses were performed with SPSS statistical software version 21.0.

\section{Ethics approval}

The study protocol adhered to guidelines for ethical conduct of Aboriginal health research, and was approved by the WA Aboriginal Health Ethics Committee (Ref.no. 589), Human Research Ethics Committee of University of WA (Ref.no. RA/4/1/2000), and Department of Health WA Human Research Ethics Committee (Ref.no. 2008/25). As de-identified data was utilised in this study, individual consent was not required.

\section{Results}

Of the total cohort of 186,468 approximately $2 \%(n=$ 3677) of individuals had records of prescription stimulant for ADHD during the study period. Table 1 shows the socio-demographic profile of the stimulant and nonstimulant groups. The age at initial stimulant use ranged from 2-25 years with a mean age 8.7 years (SD 2.3). Individuals who had stimulant were mostly male $(n=2946$, $80.1 \%)$, with non-Aboriginal parents $(n=3423,93.1 \%)$, living in metropolitan areas $(n=2212,60.2 \%)$, and were least disadvantaged $(n=1299,35.3 \%)$. Some 155 (19.5\%) individuals had at least one Aboriginal parent, represented by only an Aboriginal father in 93 instances (2.5\%), only an Aboriginal mother in $62(1.7 \%)$ and by both parents being Aboriginal in 99 (2.7\%).

\section{Ethnic and demographic differences in stimulant use}

Results of Cox regression analysis evaluating the associations between prescription stimulant use for ADHD and Aboriginality and other demographic characteristics are shown in Table 2. Both univariate and multivariate models showed that individuals with both Aboriginal parents were two-thirds less likely (adjusted HR 0.33, $95 \%$ CI $0.26-0.42, p<0.001$ ) and individuals with Aboriginal mothers only were one-third less likely (adjusted HR $0.69,95 \%$ CI $0.53-0.90, p=0.006$ ) to use stimulants than individuals of non-Aboriginals parents. The risk for stimulant use in individuals of Aboriginal fathers was not significantly different from individuals of nonAboriginal parents in either the crude or adjusted analysis. After adjusted, the association between risk for stimulant use and maternal age was marked. Individuals 
Table 1 Baseline demographic characteristics of Aboriginal and non-Aboriginal children and adolescents born in WA between 1980-2005

\begin{tabular}{|c|c|c|c|}
\hline Characteristics & & \multirow{2}{*}{$\begin{array}{l}\text { No stimulant } \\
\text { used (\%) } \\
182791\end{array}$} & \multirow{2}{*}{$\begin{array}{l}\text { Stimulant used } \\
\text { for ADHD (\%) } \\
3677\end{array}$} \\
\hline Participants & & & \\
\hline \multirow[t]{4}{*}{$\begin{array}{l}\text { Parents Aboriginal } \\
\text { status }\end{array}$} & $\begin{array}{l}\text { Non-Aboriginal } \\
\text { parents }\end{array}$ & 164290 (89.9) & $3423(93.1)$ \\
\hline & $\begin{array}{l}\text { Both parents } \\
\text { Aboriginal }\end{array}$ & $10737(5.9)$ & $99(2.7)$ \\
\hline & $\begin{array}{l}\text { Only father } \\
\text { Aboriginal }\end{array}$ & $3955(2.2)$ & $93(2.5)$ \\
\hline & $\begin{array}{l}\text { Only mother } \\
\text { Aboriginal }\end{array}$ & $3809(2.1)$ & $62(1.7)$ \\
\hline \multirow{7}{*}{$\begin{array}{l}\text { Mothers' age at } \\
\text { birth }\end{array}$} & $<20$ & $11642(6.4)$ & $345(9.4)$ \\
\hline & $20-24$ & $35823(19.6)$ & $992(27.0)$ \\
\hline & $25-29$ & $60471(33.1)$ & 1157 (31.5) \\
\hline & $30-34$ & $53085(29.0)$ & $834(22.7)$ \\
\hline & $35-39$ & $18764(10.3)$ & $299(8.1)$ \\
\hline & $\geq 40$ & $2762(1.5)$ & $44(1.2 \%)$ \\
\hline & Unknown & $244(0.1 \%)$ & $6(0.2 \%)$ \\
\hline \multirow[t]{3}{*}{ Sex } & Male & $92708(50.7)$ & $2946(80.1)$ \\
\hline & Female & $90081(49.3)$ & $731(19.9)$ \\
\hline & Unknown & $2(0.01)$ & 0 \\
\hline \multirow{4}{*}{$\begin{array}{l}\text { Geographical } \\
\text { remoteness }\end{array}$} & Metropolitan & $105567(57.8)$ & $2212(60.2)$ \\
\hline & Rural & $40332(22.1)$ & $799(21.7)$ \\
\hline & Remote & $14160(7.7)$ & $171(4.7)$ \\
\hline & Unknown & $22732(12.4)$ & $495(13.5)$ \\
\hline \multirow{6}{*}{$\begin{array}{l}\text { Socioeconomic } \\
\text { disadvantage }\end{array}$} & Least disadvantaged & $78304(42.8)$ & $1299(35.3)$ \\
\hline & Less disadvantaged & $42061(23.0)$ & $845(23.0)$ \\
\hline & Little disadvantaged & $17015(9.3)$ & $395(10.7)$ \\
\hline & More disadvantaged & $8373(4.6)$ & $183(5.0)$ \\
\hline & Most disadvantaged & $15467(8.5)$ & $489(13.3)$ \\
\hline & Unknown & $21571(11.8)$ & $466(12.7)$ \\
\hline
\end{tabular}

of mothers younger than aged 20 years had a 1.5 fold (HR 1.52, 95 \% CI 1.33-1.74, $p<0.001$ ) increased risk for stimulant use as compared to individuals of mothers aged 25-29 years, whereas a decreased risk was seen of mothers aged $30-34$ years (HR 0.88, 95 \% CI0.80-0.96, $p=0.007$ ). Boys were nearly four times more likely to be prescribed than girls (HR 3.85, $95 \%$ CI 3.53-4.20, $p<$ 0.001). Likewise, geographical remoteness was a strong determinant of the outcomes with HR ranging from 0.87 (95\% CI 0.80-0.94, $p<0.001)$ in rural to HR 0.63 (95\% CI $0.54-0.74, p<0.001)$ in remote areas compared with HR in metropolitan areas. Individuals with mostdisadvantage had a two-fold increased risk for stimulants use compared to those with least socioeconomic status (HR 2.03, 95 \% CI 1.82-2.27, $p<0.001$ ).

\section{Comparison of stimulant use between non-Aboriginals and Aboriginals living in metropolitan and non- metropolitan areas}

In the adjusted model, individuals with both Aboriginal parents were $65 \%$ less likely (HR 0.35, $95 \%$ CI $0.25-0.49$, $p<0.001)$ in metropolitan, and $72 \%$ less likely in rural and remote areas (HR 0.28, $95 \%$ CI $0.20-0.38, p<0.001$ ) to have stimulants than individuals with non-Aboriginal parents (Table 3). The HR was also lower in metropolitan, (HR 0.68, $95 \%$ CI $0.48-0.95, p=0.03$ ) and in nonmetropolitan areas (HR 0.66, $95 \%$ CI 0.44-1.0, $p=0.05$ ) for those who had only Aboriginal mothers. A 1.6 fold higher risk for stimulant use was seen in individuals of mother's younger than 20 years old (HR $1.5695 \% \mathrm{CI}$ 1.24-1.97, $p<0.001)$ compared with mother age 25-29 years old. The higher risk for stimulant use among boys was observed in both metropolitan (HR 3.69, $95 \%$ CI $3.33-4.09, p<0.001$ ) and non-metropolitan areas (HR 4.24, $95 \%$ CI 3.61-4.99, $p<0.001)$. HR was elevated by two-fold in the most-disadvantaged group compared with their least-disadvantaged counterparts (metropolitan HR 2.17, $95 \%$ CI 1.89-2.49, $p<0.001$ ), (non-metropolitan- HR 1.80, 95 \% CI 1.49-2.17, $p<0.001)$.

\section{Comparison of stimulant use within Aboriginal group}

The fitted univariate and multivariate models for stimulant use determinants in only those individuals who had any Aboriginal parents are shown in Table 4. Aboriginal boys were four times more likely to be prescribed than Aboriginal girls (HR 4.08, 95 \% CI 2.92-5.69, $p<0.001$ ). Aboriginals living in remote areas were $62 \%$ less likely (HR 0.38, $95 \% \mathrm{CI} 0.26-0.56, p<0.001$ ) to have stimulants than their city counterparts. Mothers' age and socioeconomic status were not significantly associated with stimulant use within this group. We also fitted a multiple linear regression model to examine the association between mean age at initial prescription stimulants and demographic and geographic variables, but no association was observed (results attached as Additional file 1).

\section{Discussion}

Despite increasing recognition of ADHD among Aboriginal children [12, 22, 23], the risk of stimulant use for ADHD was markedly lower among individuals of Aboriginal parents than individuals of non-Aboriginal parents in our study. Parents are unlikely to pursue ADHD medication if they do not perceive ADHD as a clinical problem [24]. Aboriginal parents who allow children freedom to explore their environment without restrictions to make them physically and emotionally resilient [25], may perceive hyperactivity and impulsivity as normal child behaviour. 
Table 2 Hazard ratios and $95 \% \mathrm{Cl}$ of prescription stimulant medication in Aboriginal and non-Aboriginal children and adolescents

\begin{tabular}{|c|c|c|c|c|c|}
\hline \multirow[t]{2}{*}{ Parameter } & & \multicolumn{2}{|c|}{ Univariate Analysis } & \multicolumn{2}{|c|}{ Multivariate Analysis ${ }^{\mathrm{a}}$} \\
\hline & & $\mathrm{HR}(95 \% \mathrm{Cl})$ & $\overline{P \text {-Value }}$ & $\mathrm{HR}(95 \% \mathrm{Cl})$ & $P$-Value \\
\hline \multirow[t]{4}{*}{ Parents Aboriginal status } & Non-Aboriginal parents & 1.0 & & 1.0 & \\
\hline & Both parents Aboriginal & $0.45(0.37-0.55)$ & $<0.001$ & $0.33(0.26-0.42)$ & $<0.001$ \\
\hline & Only father Aboriginal & $1.13(0.92-1.38)$ & 0.26 & $0.92(0.74-1.14)$ & 0.45 \\
\hline & Only mother Aboriginal & $0.78(0.61-1.01)$ & 0.059 & $0.69(0.53-0.90)$ & 0.006 \\
\hline \multirow[t]{6}{*}{ Mothers' age group in years at birth } & $<20$ & $1.54(1.36-1.73)$ & $<0.001$ & $1.52(1.33-1.74)$ & $<0.001$ \\
\hline & $20-24$ & $1.44(1.32-1.56)$ & $<0.001$ & $1.42(1.30-1.56)$ & $<0.001$ \\
\hline & $25-29$ & 1.0 & & 1.0 & \\
\hline & $30-34$ & $0.82(0.75-0.90)$ & $<0.001$ & $0.88(0.80-0.96)$ & 0.007 \\
\hline & $35-39$ & $0.84(0.74-0.95)$ & 0.006 & $0.90(0.79-1.03)$ & 0.14 \\
\hline & $\geq 40$ & $0.84(0.62-1.13)$ & 0.24 & $0.83(0.60-1.16)$ & 0.28 \\
\hline \multirow[t]{2}{*}{ Sex } & Female & 1.0 & & 1.0 & \\
\hline & Male & $3.83(3.53-4.15)$ & $<0.001$ & $3.85(3.53-4.20)$ & $<0.001$ \\
\hline \multirow[t]{3}{*}{ Geographical remoteness } & Metropolitan & 1.0 & & 1.0 & \\
\hline & Rural & $0.95(0.87-1.03)$ & 0.18 & $0.87(0.80-0.94)$ & $<0.001$ \\
\hline & Remote & $0.58(0.50-0.68)$ & $<0.001$ & $0.63(0.54-0.74)$ & $<0.001$ \\
\hline \multirow[t]{5}{*}{ Socioeconomic disadvantage } & Least disadvantaged & 1.0 & & 1.0 & \\
\hline & Less disadvantaged & $1.21(1.12-1.32)$ & $<0.001$ & $1.19(1.09-1.30)$ & $<0.001$ \\
\hline & Little disadvantaged & $1.39(1.24-1.56)$ & $<0.001$ & $1.32(1.18-1.49)$ & $<0.001$ \\
\hline & More disadvantaged & $1.31(1.12-1.53)$ & $<0.001$ & $1.31(1.12-1.53)$ & $<0.001$ \\
\hline & Most disadvantaged & $1.88(1.70-2.09)$ & $<0.001$ & $2.03(1.82-2.27)$ & $<0.001$ \\
\hline
\end{tabular}

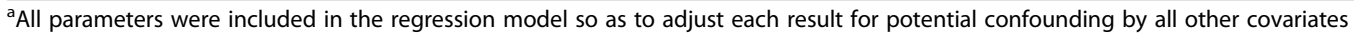

Aboriginal children were subject to removal from their families historically through systematic policy of colonial intervention, and also to a lesser extent today through out-of-homecare programs [26, 27]. Parental separation and early attachment deprivation is a risk factor for ADHD in children [28]. Aboriginal parents may attribute hyperactivity and impulsivity to child-removal-associated trauma which has been rooted in the Aboriginal cultural memory [29]. This trauma has been advanced as a reason why treatment may appear to the Aboriginal parents as a repetition of the colonial practices [30], jeopardising abilities to fulfil their roles in family and community [31].

Stimulant use was notably lower in individuals of Aboriginal mothers than fathers, possibly due to the fact that Aboriginal women traditionally play a central role in family and community, and are solely responsible for caretaking and early child socialization [32, 33]. Conversely, another study reported fathers more than mothers were associated with lower stimulant use in non-Anglophonic Australian communities [34]. The authors argued that fathers who were less likely to perceive ADHD as a problem than mothers were the decision-maker about child health in non-English speaking communities.
We found lower risk of stimulant use among Aboriginals in non-metropolitan than in metropolitan areas likely due to geographical disparities in healthcare service access with shortages of health-related infrastructure in rural areas in Australia [35]. Positive impact of community support and sense of belonging on protecting Aboriginal people against mental illness in both metropolitan and remote Aboriginal communities in Australia are documented [36, 37]. Yet, it is difficult to measure if the influence of the community support on mental health is greater in rural than metropolitan communities. In Canada, Currie et al. [38] reported that while Aboriginal enculturation was protective against substance use and strengthened psychological wellbeing, mainstream acculturation weakens the influence of cultural ties and was a risk factor for substance abuse in urban Aboriginal adults. As Aboriginal people continue to urbanize in Australia [39], they may adopt beliefs and attitudes to ADHD medication of the mainstream urban society leading to the discrepancy in stimulant use between metropolitan and remote Aboriginal communities here.

We made a number of other salient observations in this study. The first confirmed the well-known gender variation in stimulant use. Both Aboriginal and nonAboriginal boys had elevated risk of stimulant use 
Table 3 Comparison of stimulant medication in Aboriginal and non-Aboriginal children by metropolitan and non-metropolitan areas

\begin{tabular}{|c|c|c|c|c|c|}
\hline \multirow[t]{3}{*}{ Parameter } & & \multirow{2}{*}{\multicolumn{2}{|c|}{$\frac{\text { Multivariate Analysis }}{\text { Metro }}$}} & \multirow{2}{*}{\multicolumn{2}{|c|}{$\begin{array}{l}\text { Multivariate Analysis }^{a} \\
\text { Non-Metro }\end{array}$}} \\
\hline & & & & & \\
\hline & & $\mathrm{HR}(95 \% \mathrm{Cl})$ & $P$-Value & \multirow{2}{*}{$\begin{array}{l}\text { HR }(95 \% \text { Cl) } \\
1.0\end{array}$} & \multirow[t]{2}{*}{$P$-Value } \\
\hline \multirow[t]{4}{*}{ Parents Aboriginal status } & Non-Aboriginal parents & 1.0 & & & \\
\hline & Both parents Aboriginal & $0.35(0.25-0.49)$ & $<0.001$ & $0.28(0.20-0.38)$ & $<0.001$ \\
\hline & Only father Aboriginal & $0.96(0.73-1.26)$ & 0.76 & $0.8(0.55-1.17)$ & 0.26 \\
\hline & Only mother Aboriginal & $0.68(0.48-0.95)$ & 0.03 & $0.66(0.44-1.0)$ & 0.051 \\
\hline \multirow[t]{6}{*}{ Mothers' age group in years at birth } & $<20$ & $1.51(1.28-1.78)$ & $<0.001$ & $1.56(1.24-1.97)$ & $<0.001$ \\
\hline & $20-24$ & $1.48(1.33-1.66)$ & $<0.001$ & $1.30(1.10-1.53)$ & 0.002 \\
\hline & $25-29$ & 1.0 & & 1.0 & \\
\hline & $30-34$ & $0.89(0.79-1.00)$ & 0.04 & $0.85(0.71-1.01)$ & 0.07 \\
\hline & $35-39$ & $0.85(0.73-1.00)$ & 0.57 & $1.06(0.82-1.35)$ & 0.67 \\
\hline & $\geq 40$ & $0.78(0.52-1.16)$ & 0.22 & $1.00(0.55-1.82)$ & 0.99 \\
\hline \multirow[t]{2}{*}{ Sex } & Female & 1.0 & & 1.0 & \\
\hline & Male & $3.69(3.33-4.09)$ & $<0.001$ & $4.24(3.61-4.99)$ & $<0.001$ \\
\hline \multirow[t]{5}{*}{ Socioeconomic disadvantage } & Least disadvantaged & 1.0 & & 1.0 & \\
\hline & Less disadvantaged & 1.19(1.07-1.33) & $<0.001$ & 1.15(0.98-1.35) & 0.10 \\
\hline & Little disadvantaged & $1.33(1.16-1.53)$ & $<0.001$ & $1.28(1.04-1.58)$ & 0.02 \\
\hline & More disadvantaged & 1.4(1.16-1.69) & $<0.001$ & $1.13(0.85-1.49)$ & 0.41 \\
\hline & Most disadvantaged & $2.17(1.89-2.49)$ & $<0.001$ & $1.80(1.49-2.17)$ & $<0.001$ \\
\hline
\end{tabular}

${ }^{a}$ All parameters were included in the regression model so as to adjust each result for potential confounding by all other covariates

Table 4 Hazard ratios and $95 \% \mathrm{Cl}$ of prescription stimulant medication in Aboriginal children and adolescents

\begin{tabular}{|c|c|c|c|c|c|}
\hline \multirow[t]{2}{*}{ Parameter } & & \multicolumn{2}{|c|}{ Univariate Analysis } & \multicolumn{2}{|c|}{ Multivariate Analysis $^{a}$} \\
\hline & & $\mathrm{HR}(95 \% \mathrm{Cl})$ & $P$-Value & $\mathrm{HR}(95 \% \mathrm{Cl})$ & $P$-Value \\
\hline \multirow[t]{6}{*}{ Mothers' age group in years at birth } & $<20$ & $0.70(0.47-10.4)$ & 0.08 & $0.69(0.45-1.07)$ & 0.10 \\
\hline & $20-24$ & $1.10(0.80-1.50)$ & 0.56 & $1.20(0.85-1.69)$ & 0.29 \\
\hline & $25-29$ & 1.0 & & 1.0 & \\
\hline & $30-34$ & $1.06(0.72-1.57)$ & 0.78 & $1.30(0.86-1.96)$ & 0.22 \\
\hline & $35-39$ & $0.98(0.54-1.77)$ & 0.94 & $1.25(0.68-2.28)$ & 0.48 \\
\hline & $\geq 40$ & $0.46(0.06-3.33)$ & 0.44 & $0.60(0.08-4.33)$ & 0.61 \\
\hline \multirow[t]{2}{*}{ Sex } & Female & 1.0 & & 1.0 & \\
\hline & Male & $4.51(3.27-6.23)$ & $<0.001$ & $4.08(2.92-5.69)$ & $<0.001$ \\
\hline \multirow[t]{3}{*}{ Geographical remoteness } & Metropolitan & 1.0 & & 1.0 & \\
\hline & Rural & $0.83(0.61-1.13)$ & 0.23 & $0.82(0.60-1.12)$ & 0.20 \\
\hline & Remote & $0.39(0.27-0.58)$ & $<0.001$ & $0.38(0.26-0.56)$ & $<0.001$ \\
\hline \multirow[t]{5}{*}{ Socioeconomic disadvantage } & Least disadvantaged & 1.0 & & 1.0 & \\
\hline & Less disadvantaged & $1.05(0.68-1.63)$ & 0.82 & $1.15(0.74-1.78)$ & 0.53 \\
\hline & Little disadvantaged & $1.25(0.78-1.99)$ & 0.35 & $1.29(0.81-2.05)$ & 0.29 \\
\hline & More disadvantaged & $1.10(0.65-1.88)$ & 0.71 & $1.26(0.74-2.16)$ & 0.39 \\
\hline & Most disadvantaged & $1.14(0.76-1.72)$ & 0.53 & $1.40(0.92-2.12)$ & 0.12 \\
\hline
\end{tabular}


possibly due to the fact that boys commonly manifest hyperactivity and impulsivity [40] which may closely entwine with heuristics and gender stereotypes influencing referral [41] and diagnose [42]. Secondly, the association between young maternal age and increased stimulant use risk is well established [43-45]. A high level of maternal depression, smoking and substance use during pregnancy has been reported as risk factors for ADHD in children [44, 45]. This association however was not marked in Aboriginal groups here, and may need further research. Thirdly, associations between socioeconomic hardship and increased stimulant use was in line with previous Australian studies $[34,40]$. While a high prevalence of ADHD in marginalised children is well established [10, 46], a large proportion of Australian children living in poverty were reported as being treated without meeting the ADHD diagnosis criteria [47, 48]. Hence, disadvantaged children who are more likely to be diagnosed with ADHD represent an important public health issue. Yet our findings of no association between disadvantage and stimulant use within Aboriginal groups is novel, however different interpretations exist and further investigation is warranted. One possibility is that within the Aboriginal population, social disadvantage correlates with ADHD symptoms and with a tendency not to receive treatment. Community support and cultural bond which have been shown to buffer mental and behavioural problems for marginalised people [49] could be another explanation.

Some limitations need to be considered when interpreting our results. The datasets did not permit identification of individuals diagnosed with ADHD but not prescribed stimulants. It would have been useful to examine differences between diagnosis rates and stimulant treatment in Aboriginal children to investigate the likelihood of stimulant over- or under-prescribing. In order to correctly identify Aboriginal people we triangulated information from two data sources; yet, it is still possible that Aboriginality is under-reported or misreported. It is also possible that our results were affected by unmeasured and, as yet, unidentified confounders.

\section{Conclusion}

Lower stimulant use for ADHD in children and adolescents of Aboriginal parents in our study suggests either Aboriginal parent perceive ADHD symptoms as normal child behaviour, have a negative attitude towards medication, or cultural competency provides a coping mechanism to make the ADHD symptoms functional. Alternatively, Aboriginal children who would stand to benefit from ADHD medication may face barriers to access. Aboriginal children should be protected from misdiagnosis and over-diagnosis; however, great care should be taken to ensure full access to appropriate services when required. A better understanding of Aboriginal perceptions of ADHD and stimulant treatment is crucial to identify vulnerabilities and develop targeted interventions and policy that account for social factors and align with Aboriginal culture to provide optimal care. We suggest two avenues for future research examining ADHD prevalence in Aboriginal children with narrowing of focus: first, for the rate of ADHD diagnosis and stimulant treatment to be investigated; and second, qualitative research to explore Aboriginal perception towards ADHD and stimulant treatment.

\section{Additional file}

Additional file 1: Mean age in years at initial prescription in those receiving a stimulant medication for ADHD according to cultural and demographic factors. (DOCX $18 \mathrm{~kb}$ )

\section{Abbreviations}

ADHD: Attention Deficit Hyperactivity Disorder; ARIA: Accessibility/ Remoteness Index of Australia; HR: Hazards Ratios; IRSD: Index of Relative Socio-Economic Disadvantage; MNS: Midwives' Notification System; SEIFA: Socio-Economic Indexes for Areas; WA: Western Australia.

\section{Competing interests}

MG, CDJH, and DJP declare that they have no competing interests.

\section{Authors' contributions}

MG and CDJH participated in the conception, study design and formulation of data analysis plan. MG carried out the data analysis, and prepared the manuscript. CDJH reviewed the manuscript and contributed to the discussion. DBP critically revised the manuscript for important intellectual content and advised on the method. All authors read and approved the final manuscript.

\section{Acknowledgements}

We are thankful to the Data Linkage Unit, WA Department of Health for extracting, linking and providing access to the datasets. We also thank the custodians of the pharmaceutical, genealogical and midwives data collection at the WA Department of Health, WA Registry of Births and Deaths for the provision of service data for this investigation.

Received: 24 July 2015 Accepted: 18 November 2015

Published online: 09 December 2015

\section{References}

1. Barkley RA, Cook EH, Diamond A, Zametkin A, Thapar A, Teeter A. International consensus statement on ADHD. Clin Child Fam Psychol Rev. 2002:5(2):89-111.

2. Van der Oord S, Prins P, Oosterlaan J, Emmelkamp P. Efficacy of methylphenidate, psychosocial treatments and their combination in school-aged children with ADHD: a meta-analysis. Clin Psychol Rev. 2008;28:783-800.

3. Prosser B. Attention deficit hyperactivity disorder in Australia: perspectives from the sociology of deviance. J Soc. 2015;51(3):596-612.

4. Russell G, Ford T, Rosenberg R, Kelly S. The association of attention deficit hyperactivity disorder with socioeconomic disadvantage: alternative explanations and evidence. J Child Psychol Psychiatry. 2014;55(5):436-45.

5. Nigg J, Craver L. ADHD and social disadvantage: an inconvenient truth? a reflection on Russell et al. (2014) and Larsson et al. J Child Psychol Psychiatry. 2014;55(5):446-7.

6. Thomas R, Mitchell G, Batstra L. Attention-deficit/hyperactivity disorder: are we helping or harming? BMJ. 2013;347:f6172. doi:10.1136/bmj.f6172).

7. Zubrick S, Silburn S, Lawrence D, Mitrou F, Dalby R: The Western Australian Aboriginal child health survey: the social and emotional wellbeing of 
Aboriginal children and young people. In. Perth: Curtin University of Technology and Telethon Institute for Child Health Research; 2005.

8. Moore E, Sunjic S, Kaye S, Archer V, Indig D: Adult ADHD among NSW prisoners: prevalence and psychiatric comorbidity. J Atten Disord 2013, doi: 10.1177/1087054713506263.

9. Miller S, Spooner C: Difersion of Aboriginal and Torres Strait Islander youth from juvenile detention: a report to the Australian National Council on Drugs. In. Canberra: Australian National Council on Drugs; 2003.

10. Russell AE, Ford T, Russell G. Socioeconomic associations with ADHD: findings from a mediation analysis. PLoS One. 2015;10(6):e0128248. doi:10.1371/journal.pone.0128248.

11. Ogundele M, DeSoysa R, Omenaka I. How does socio-economic deprivation affect the prevalence of ADHD in North West of England? Arch Dis Child. 2012;97 Suppl 1:A1-186.

12. Baydala L, Sherman J, Rasmussen C, Wikman E, Janzen H. ADHD characteristics in Canadian Aboriginal children. J Atten Disord. 2006;9(4): 642-7.

13. Ypinazar V, Margolis S, Haswell-Elkins M, Tsey K. Indigenous Australians' understandings regarding mental health and disorders. Australasian Psychiatry. 2007:41:467-78.

14. Browne-Yung K, Ziersch A, Baum F, Gallaher G. Aboriginal Australians' experience of social capital and its relevance to health and wellbeing in urban settings. Soc Sci Med. 2013;97:20-8.

15. Kelman C, Bass A, Holman C. Research use of linked health data - a best practice protocol. Aust N Z J Public Health. 2002;26(3):251-5.

16. Holman CDJ, Bass AJ, Rouse IL, Hobbs MST. Population-based linkage of health records in Western Australia: development of a health services research linked database. Aust N Z J Public Health. 1999;23(5):453-9.

17. Glasson EJ, de Klerk N, Bass AJ, Rosman DL, Palmer L, Holman CDJ. Cohort profile: the Western Australian family connections genealogical project. Int J Epidemiol. 2008;37(1):30-5.

18. Randall DA, Leyland AH, Jorm LR. Statistical methods to enhance reporting of Aboriginal Australians in routine hospital records using data linkage affect estimates of health disparities. Aust N Z J Public Health. 2013;37(5): $442-9$.

19. Lawrence D, Christensen D, Mitrou F, Draper G, Davis G, McKeown S Adjusting for under-identification of Aboriginal and/or Torres Strait Islander births in time series produced from birth records: using record linkage of survey data and administrative data sources. BMC Med Res Methodol. 2012; 12:90-102.

20. Australian Bureau of Statistics: Information paper. ABS views on remoteness. Canberra (ABS, Cat no 12440) 2001.

21. Australian Bureau of Statistics: Information paper: an introduction to socioeconomic indexes for areas (SEIFA). Canberra (ABS, 2006 Cat no 20390) 2008.

22. Schmidt SL, Simoes EDN, Schmidt GJ, Schmidt MJ. Epidemiology of attention deficit disorder in Brazil: implications for the Brazilian legal system. Open J Epidemiol. 2013;3:232-6.

23. Azevedo P, Caixeta L, Andrade L, Bordin I. Attention deficit/hyperactivity disorder symptoms in indigenous children from the Brazilian Amazon. Arq Neuropsiquiatr. 2010;68(4):541-4.

24. Fiks A, Mayne S, DeBartolo E, Power T, Guevara J. Parental preferences and goals regarding ADHD treatment. Pediatrics. 2013;132:692-703.

25. Warrki Jarrinjaku ACRS Project Team. Warrki Jarrinjaku Jintangkamanu Purananjaku - 'working together everyone and listening', Aboriginal child rearing and associated research: a review of the literature. Canberra: Department of Family and Community Services; 2002.

26. Cunneen C, Libesman T. Postcolonial trauma: the contemporary removal of Indigenous children and young people from their families in Australia. Aust J Soc Issues. 2000;35(2):99-115.

27. Bromfield L, Holzer P. A national approach for child protection - project report, National child protection clearinghouse Australian Institute of Family Studies. 2008.

28. Roskam I, Stievenart M, Tessier R, Muntean A, Escobar M, Santelices M, et al. Another way of thinking about ADHD: the predictive role of early attachment deprivation in adolescents' level of symptoms. Soc Psychiatry Psychiatr Epidemiol. 2014;49:133-44.

29. Duran E, Duran B. Native American post-colonial psychology. Albany: State University of New York Press; 1995.

30. Oldani MJ. Uncanny scripts: understanding pharmaceutical emplotment in the Aboriginal context. Transcult Psychiatry. 2009;46:131-56.
31. Vicary D, Westerman T. That's just the way he is': some implications of Aboriginal mental health beliefs. AeJAMH. 2004;3(3):1-10.

32. Pattel N. Aboriginal families, cultural context and therapy. Counselling Psychotherapy Health. 2007;3(1):1-24.

33. Australian Bureau of Statistics: Aboriginal and Torres Strait Islander wellbeing: a focus on children and youth. Canberra (ABS, Cat no 47250) 2011.

34. Ghosh M, Holman CDJ, Preen D. Exploring parental country of birth differences in the use of psychostimulant medications for ADHD: a wholepopulation linked data study. Aust N Z J Public Health. 2015;39(1):88-92.

35. Smith KB, Humphreys JS, Wilson MG. Addressing the health disadvantage of rural populations: how does epidemiological evidence inform rural health policies and research? Aust J Rural Health. 2008;16:56-66.

36. Waterworth P, Rosenberg M, Braham R, Pescud M, Dimmock J. The effect of social support on the health of Indigenous Australians in a metropolitan community. Soc Sci Med. 2014;119:139-46.

37. Berry HL. Social capital and mental health among Aboriginal Australians, New Australians and other Australians living in a coastal region. AeJAMH. 2009;8(2):142-54.

38. Currie CL, Wild TC, Schopflocher DP, Laing L, Veugelers P. Illicit and prescription drug problems among urban Aboriginal adults in Canada: the role of traditional culture in protection and resilience. Soc Sci Med. 2013;88: $1-9$.

39. Australian Bureau of Statistics: The health and welfare of Australia's Aboriginal and Torres Strait Islander peoples. Canberra (ABS, Cat no 47040) 2010.

40. Calver J, Preen D, Bulsara M, Sanfilippo MF. Stimulant prescribing for the treatment of ADHD in Western Australia: socioeconomic and remoteness differences. MJA. 2007;186:124-7.

41. Sciutto MJ, Nolfi CJ, Bluhm C. Effects of child gender and symptom type on referrals for ADHD by elementary school teachers. J Emot Behav Disord. 2004;12(4):247-53.

42. Bruchmuller K, Margraf J, Schneider S. Is ADHD diagnosed in accord with diagnostic criteria? overdiagnosis and influence of client gender on diagnosis. J Consult Clin Psychol. 2012;80(1):128-38.

43. Chudal R, Joelsson P, Gyllenberg D, Lehti V, Leivonen S, Hinkka-Yli-Salomäki S. Parental age and the risk of Attention-Deficit/Hyperactivity Disorder: a nationwide, population-based cohort study. J Am Acad Child Adolesc Psychiatry. 2015;54(6):487-94.

44. Galéra C, Côté S, Bouvard M. Early risk factors for hyperactivity-impulsivity and inattention trajectories from age 17 months to 8 years. Arch Gen Psychiatry. 2011;68:1267-75.

45. Gustafsson P, Källén K. Perinatal, maternal, and fetal characteristics of children diagnosed with attentiondeficit-hyperactivity disorder: results from a population-based study utilizing the Swedish Medical Birth Register. Dev Med Child Neurol. 2011;53:263-70.

46. Ouyang L, Fang X, Mercy J, Perou R, Grosse S. Attention-deficit/hyperactivity disorder symptoms and child maltreatment: a population-based study. J Pediatr. 2008;153(6):851-6.

47. Harwood V. The new outsiders: ADHD and disadvantage. In: Graham L, editor. (De) Constructing ADHD: critical guidance for teachers and teacher educatiors. New York: Peter Lang; 2010. p. 119-42.

48. Sawyer M, Rey J, Graetz B, Clark J, Baghurst P. Use of medication by young people with attention-deficit/hyperactivity disorder. MJA. 2002;177:21-5.

49. Sampson RJ, Morenoff JD, Gannon-Rowley T. Assessing "neighborhood effects": social processes and new directions in research. Annu Rev Sociol. 2002;28:443-78.

\section{Submit your next manuscript to BioMed Central and we will help you at every step:}

- We accept pre-submission inquiries

- Our selector tool helps you to find the most relevant journal

- We provide round the clock customer support

- Convenient online submission

- Thorough peer review

- Inclusion in PubMed and all major indexing services

- Maximum visibility for your research

Submit your manuscript at www.biomedcentral.com/submit 